\title{
Lousa terapêutica como ferramenta de comunicação multidisciplinar no cumprimento do plano terapêutico em UTI cardiológica
}

\author{
Autores: Carolina F.Vasco, Guilherme D'Andrea Saba Arruda,Janaina Moreno Garcia,Carla \\ Aparecida de Moraes, Andre Feldman \\ Intituição: Rede D'OR São Luiz Anália Franco
}

\section{Introdução:}

Um dos maiores desafios humanos é a adequada comunicação interpessoal. Para garantir qualidade e segurança no atendimento ao paciente, o cuidado centrado no indivíduo deve ser prioridade, fortalecendo o processo de cuidar, assegurado pela boa comunicação interprofissional. Estabelecer diálogo com - paciente e seus familiares ou responsáveis contribui para ajustar 0 planejamento terapêutico as suas necessidades, respeitar as crenças e cultura do paciente e atender as expectativas das partes.

\section{Objetivo:}

Estabelecer maneiras para aprimorar a comunicação da equipe multidisciplinar com os pacientes na transição dos cuidados e efetividade no entendimento das metas estabelecidas no plano terapêutico.

\section{Resultados:}

Utilização da lousa terapêutica multidisciplinar como ferramenta de comunicação multidisciplinar. Trata-se de um quadro interativo e dinâmico, localizado no leito do paciente, onde a equipe multidisciplinar registra os próximos passos da assistência para o cumprimento do plano terapêutico. Neste quadro há um local destinado aos pacientes e familiares podendo ser registrada dúvidas a respeito da assistência, assim como recados para a equipe com particularidades do paciente com foco em humanização e cuidado centrado no indivíduo.

\section{Conclusão:}

Os profissionais da saúde somente conseguirão oferecer tratamento e assistência de forma integral e humanitária, quando incluírem em seu plano de cuidado a preocupação também com aspectos da área de comunicação, buscando estabelece-la de maneira efetiva e compreensível para pacientes e familiares e que atenda às suas necessidades $e$ anseios, interagindo com eles, resolvendo problemas relacionados com a abrangência da doença e seus efeitos na vida familiar, apontando soluções e propiciando melhora da sua condição de saúde.

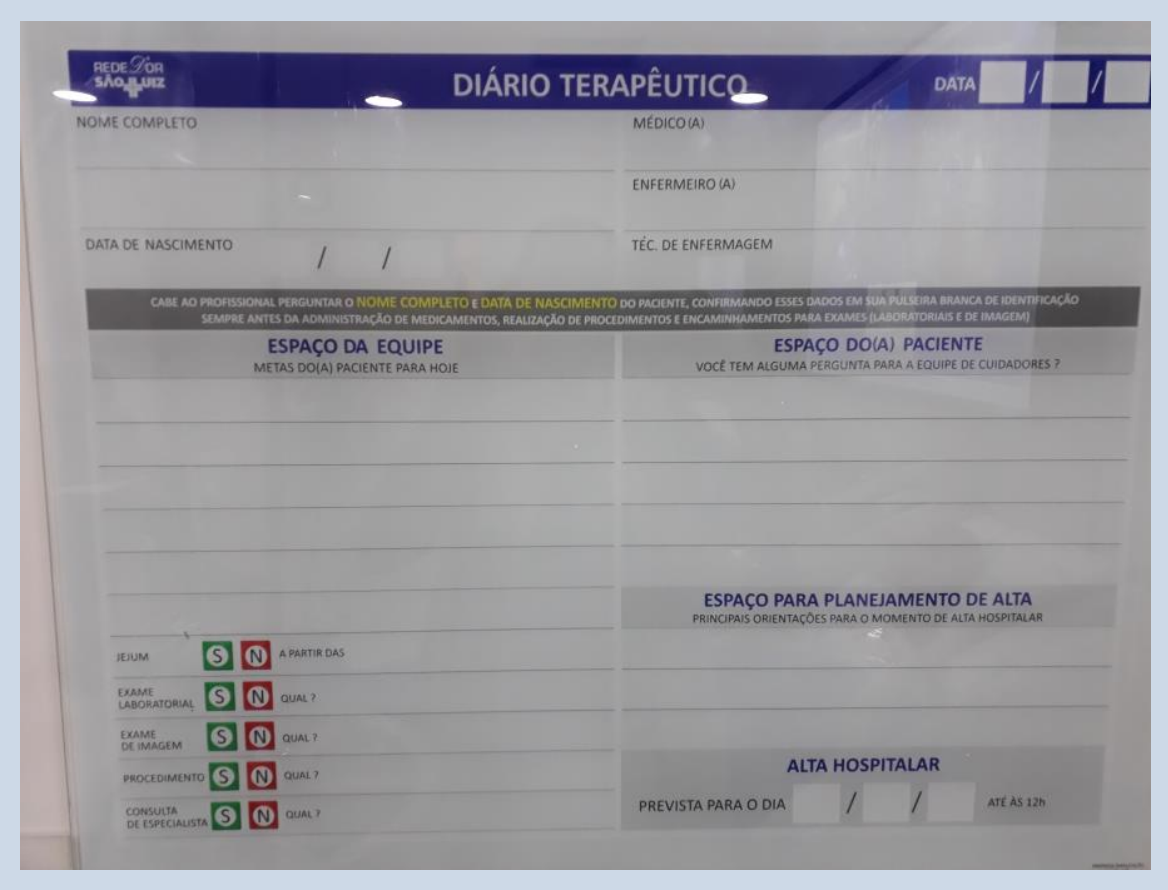

\section{Referências Bibliográficas:}

1. Miliorini JP, Fernandes MV, Decesaro MN, Marco SS. A família no contexto hospitalar: aprendendo os anseios e expectativas relacionadas com a doença crônica. Rev. Rene. Fortaleza, v. 9, n. 3, p. 81-91, jul./set.2008

2. Pontes AC, Leitão MTA, Ramos I. Comunicação terapêutica em Enfermagem: instrumento essencial do cuidado. Rev Bras Enferm, Brasília 2008 maio. 